\title{
Novel Manganese Adipate Nanoparticles as Stable Anode Materials for Lithium-ion Batteries
}

\author{
Hailong Fei ${ }^{1,2, *}$, Tan $\mathrm{Xu}^{1}$, Yumin $\mathrm{Chen}^{1}$ \\ ${ }^{1}$ State Key Laboratory of Photocatalysis on Energy and Environment, College of Chemistry, Fuzhou \\ University, Fuzhou, Fujian 350002, China. \\ ${ }^{2}$ Key Laboratory of Advanced Energy Materials Chemistry (Ministry of Education), Nankai \\ University, Tianjin 300071. \\ *E-mail: hailongfei@fzu.edu.cn
}

doi: $10.20964 / 2018.10 .19$

Received: 8 June 2018 / Accepted: 21 July 2018 / Published: 1 September 2018

It is important to seek inexpensive and environmentally friendly electrode materials for energy storage and conversion. Manganese adipate coordination polymer nanoparticles are first found to be an anode material for lithium-ion batteries. The second discharge capacity of the anode is as high as $439 \mathrm{mAh} \mathrm{g}^{-}$ ${ }^{1}$ at a current density of $200 \mathrm{~mA} \mathrm{~g}^{-1}$. A reversible capacity of $454.8 \mathrm{mAh} \mathrm{g}^{-1}$ remained after 100 cycles. In addition, a reversible reaction mechanism was proposed.

Keywords: Coordination polymer; Lithium-ion battery; Dicarboxylic acid

\section{FULL TEXT}

(C) 2018 The Authors. Published by ESG (www.electrochemsci.org). This article is an open access article distributed under the terms and conditions of the Creative Commons Attribution license (http://creativecommons.org/licenses/by/4.0/). 